\title{
Google Earth imagery coupled with on-screen digitisation for urban land use mapping: case study of Hambantota, Sri Lanka
}

\author{
SK Madarasinghe ${ }^{1}$, KKAS Yapa ${ }^{1}$ and LP Jayatissa ${ }^{2}$ \\ ${ }^{1}$ Department of Physics, Faculty of Science, University of Ruhuna, Matara. \\ ${ }^{2}$ Faculty of Graduate Studies, University of Ruhuna, Matara.
}

Submitted: 24 February 2020; Revised: 26 June 2020; Accepted: 18 August 2020

\begin{abstract}
Monitoring of land use changes using remote sensing techniques in urban areas is important in appraising urban development and environmental sustainability. However, when considering the cost-effectiveness and mapping accuracy, selection of a proper data source and an image classification technique has become a challenge, especially for researchers in the developing countries. This study, hence, aimed at investigating the effectiveness of two image sources, Google Earth and Landsat 8 as well as two classification methods, pixel- based classification and on-screen digitisation, in studying land use changes in Hambantota urban area covering a land area of about 4,000 hectares. Land use maps were created applying the two aforementioned classification techniques on the two open source images in different combinations to select the best option for studying land use changes in smaller urban areas. Results show that the overall accuracy of pixelbased classification for Landsat 8 and Google Earth images are $62.6 \%$ and $59.1 \%$, respectively, whereas on-screen digitisation of Google Earth imagery resulted in the highest overall accuracy of $88.4 \%$. Therefore, Google Earth images with on-screen digitisation increased the accuracy of the land use map by $25.8 \%$ and $29.3 \%$, respectively, compared to land use maps created by pixel-based classification of Landsat 8 and Google Earth images. Further, classification accuracies of paddy lands and sandy areas were improved by $74 \%$ and $61 \%$, respectively, when on-screen digitisation method was applied to Google Earth images compared to pixel-based classification of Landsat 8 and Google Earth images. Therefore, use of on-screen digitisation method on Google Earth imagery is recommended as a cost-effective and high accuracy method for land use mapping of smaller urban areas, particularly, in developing countries.
\end{abstract}

Keywords: Accuracy assessment, Google Earth imagery, image classification, Landsat 8 imagery, maximum likelihood method, urban development.

\section{INTRODUCTION}

Continuous monitoring of changes in urban areas, in particular, booming cities in developing countries is imperative to understand the environmental sustainability with the increase of development projects (Schneider et al., 2010). Therefore, accurate and timely information is an essential component in urban development management (Liu et al., 2018). In response to this growing necessity, several remote sensing techniques have been developed in mapping (Potere et al., 2009; Schneider et al., 2010; López-Moreno et al., 2019) using data sources such as IKONOS, Sentinel, QuickBird, SPOT, MODIS, Landsat, etc. (Bagan \& Yamagata, 2012; Gong et al., 2013; Pahlevan et al., 2017). Among these, data from Landsat series has been widely used by researchers for mapping of urban land globally (Sexton et al., 2013; Song et al., 2016; Sun et al., 2017). Selection of a data source mainly depends on the spatial, temporal and spectral resolution of images and their costs. However, objectives and the classification technique used by the researcher for land use/land cover mapping also play a considerable role on the quality of the output (Lu \& Weng, 2007). Image classification techniques in remote sensing, i.e. assigning land cover classes to pixels, have received considerable

"Corresponding author (sandunikm89@gmail.com; (D https://orcid.org/0000-0002-8594-7476) 
attention with the development of high resolution sensor platforms (Eastman, 1999). Among these, unsupervised and supervised image classification techniques (or commonly known as pixel-based classification) are widely used by many researchers. Object-based classification is found to be more useful for data with high spatial resolution. In many studies, maximum likelihood classification algorithm has been used (Otukei \& Blaschke, 2010; Shivakumar \& Rajashekararadhya, 2018). Many factors such as selection of suitable remote sensing data, spatial resolution of the target area image and complexity of landscape, image processing, and the classification approach affect the success and accuracy of a classification (Jensen \& Cowen, 1999; Phinn et al., 2000; Lu \& Weng, 2007; Warnasuriya et al., 2018). Eventhough commercial Earth observation satellites such as WorldView $(0.3 \mathrm{~m})$, SPOT $(6 \mathrm{~m})$ and QuickBird $(0.6 \mathrm{~m})$ provide high quality satellite images with high spatial resolution, the high cost and narrow spatial coverage limit the use, specially by scientists in developing countries (Lu \& Weng, 2007; Reddy, 2008; $\mathrm{Hu}$ et al., 2013). Alternatively, many researchers tend to use data from moderate resolution satellite images, for instance Landsat and Sentinel which are freely accessible to all (Phua et al., 2008; Huang et al., 2009; Remus et al., 2014). Landsat satellite images have become more attractive due to their comparatively high temporal resolution (sixteen days) and global coverage (Warnasuriya et al., 2018).

Urban land use mapping has become a challenge due to its high spatial and spectral diversity of surface materials (Thapa \& Murayama, 2009). The suitability and applicability of different classification approaches in urban land use mapping using images from two different sensors, which are publicly available without cost to researchers are examined in this study with the aim of choosing the most appropriate approach for a highly fragmented urban area. This study also attempts to fill the knowledge gap on accuracy assessment and comparison of different classification approaches.

The conventional method of land use mapping is to download relevant satellite images and run a pixel-based classification using GIS software. However, Herold et al. (2002) has reported that for areas with high land use fragmentation, use of pixel-based classification on moderate resolution images from Landsat results in an increase of classification error. In this context, use of Google Earth images, which are freely accessible and have higher resolution, has become a better alternative (Mering et al., 2010). In addition, it provides a continuous series of archives since 2005, which is much useful in spatio-temporal change detections. However, there are some challenges when using Google Earth images for land use/land cover mapping due to their poor spectral information, as they contain only Red, Green and Blue bands (Yu \& Gong, 2011). Myint et al. (2011) has reported that when land use/land cover mapping is done for urban areas using pixel-based classification on Google Earth images, their fine spatial resolution with high level of detail could lead to lower accuracy. One possible solution to overcome this drawback is to practice on-screen digitisation in place of pixel-based classification. On-screen digitisation, also referred to as heads-up digitisation, has been used in land use mapping (Shalaby, 2012). It is more time consuming than pixelbased classification when large areas are taken for the classification. Therefore, the main objective of this study is to study the possibility of using Google Earth satellite images as an alternative to moderate resolution satellite images from Landsat 8 and also to identify the most suitable classification method from pixel-based classification and on-screen digitisation technique, for land use/cover mapping for relatively smaller urban areas. Accuracy obtained for each different land use mapping approach examined here can be used as a basis for recommending the most appropriate approach for land use mapping for urban areas.

\section{METHODOLOGY}

In this study, classification accuracies of land use maps created using pixel-based classification and on-screen digitisation are compared to select the best method for land use classification of a smaller urban area with open source images. First, conventional pixel-based classification was implemented on Landsat 8 images to produce land use map of the area of interest. On-screen digitisation on Landsat images was not performed due to its low spatial information at $30 \mathrm{~m}$ resolution (max. of $15 \mathrm{~m}$ with pan sharpening), although it contains rich spectral information (Sivanpillai \& Miller, 2008). Second, Google Earth archive images were used to make land use maps of the same area using both pixel-based classification and on-screen digitisation techniques.

Hambantota urban area (about 4012 ha) situated in the southern coast of Sri Lanka with latitudes ranging from $6^{\circ} 6^{\prime} 31^{\prime \prime} \mathrm{N}$ to $6^{\circ} 10^{\prime} 48^{\prime \prime} \mathrm{N}$ and longitudes ranging from $81^{\circ} 4^{\prime} 0^{\prime \prime} \mathrm{E}$ to $81^{\circ} 8^{\prime} 53^{\prime \prime} \mathrm{E}$ was selected as the study area. It comprises five Grama Niladhari (GN) divisions (Figure 1), within which several development projects had been completed during the last few years including the Hambantota port and Mirijjavila cement factory. As the study area has a high land use fragmentation, it is important to assess the degree of classification error due to selection of classification techniques. 


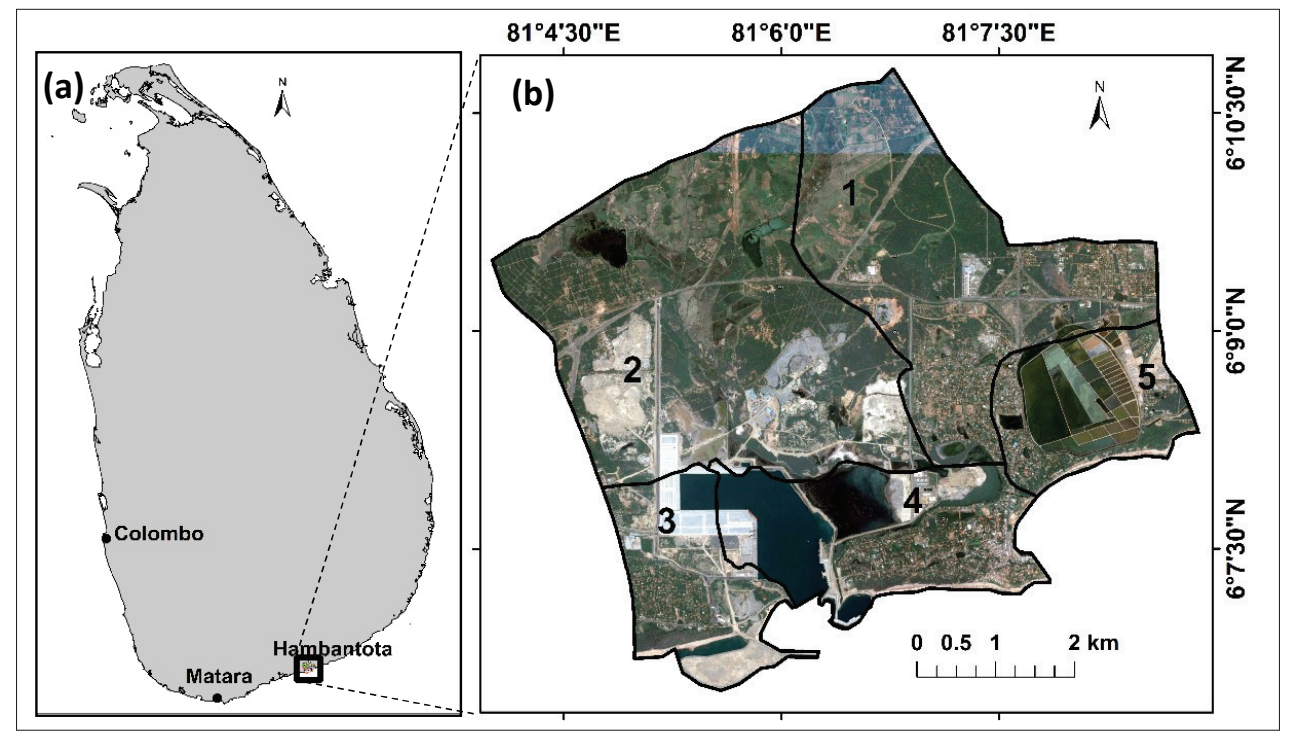

Figure 1: (a) Map of Sri Lanka showing the location of the study area, indicated by a small black square; (b) Google Earth image of the study area taken on 02.12.2016. Black lines demarcate GN divisions of the study area; 1- Siribopura (1069 ha), 2- Samodagama (1556 ha), 3- Mirijjavila (396 ha), 4- Hambantota West (604 ha) and 5- Hambantota East (387 ha).

\section{Remote sensing and image processing}

Land use/land cover maps of the study area were created, first using pixel-based classification technique for Landsat 8 and Google Earth images and then, using onscreen digitisation technique for Google Earth imagery. The two open sources, USGS Earth explorer (Landsat 8) and Google Earth Pro were used to obtain images.

\section{Pixel-based classification of Landsat 8 imagery}

Landsat 8 OLI/TIRS satellite image of $10^{\text {th }}$ November 2016 (path/row: 141/56), covering the study area was downloaded in separate bands. Blue (band 2), green (band 3), red (band 4) and near infrared (band 5) bands having a spatial resolution of $30 \mathrm{~m}$ and panchromatic (band 8) band with $15 \mathrm{~m}$ spatial resolution were imported to ArcMapv.10.1. A true colour composite was created followed by a pan-sharpening using panchromatic band to increase the spatial resolution of the image to $15 \mathrm{~m}$. Different land uses were identified using image attributes and the image was classified into seven classes; water, natural vegetation, paddy, minor crops, built-up area, sand and bare soil, using pixel-based classification with maximum likelihood method. False colour composite was also taken into consideration to identify different land use/land cover types. Area statistics of each land use class was estimated.

\section{Pixel-based classification of Google earth imagery}

High resolution satellite images of $05^{\text {th }}$ January 2017 (source: CNES/Airbus - closest date of cloud free images available to the date of Landsat image), covering the study area were downloaded at $4 \mathrm{~km}$ eye altitude from Google Earth Pro archives. Six images were required to cover the whole study area. These images were taken into ArcMapv.10.1 (ESRI, USA) interface and geo-referenced using 4-7 ground control points per image, having root mean square error (RMSE) less than 0.5. Spatial resolution of the geo-referenced Google Earth images was $4.1 \mathrm{~m}$. All six images were then mosaicked and the study area was extracted. Different land uses were identified taking image attributes such as texture, tonality, structure and size into consideration and classified into the same aforementioned classes using maximum likelihood classification technique in ArcMap v.10.1. Area estimation of each land use class was carried out using the same GIS software.

\section{On-screen digitisation of Google Earth imagery}

The same mosaicked Google Earth image used for pixelbased classification discussed above was used for this classification method as well. Different land uses were identified taking image attributes into consideration. Manual digitisation of the land use/cover features was done on-screen in ArcMap, taking the same seven 
different land use classes into account. Finally, area statistics were derived for each land use class.

Although Google Earth image allows identification of many different land use classes, Landsat 8 image was taken as the limiting factor in deciding the number of classes and all images were classified into the same seven different classes to avoid confusion in area comparison and accuracy assessment. Area statistics derived under all three methods were recorded and compared. To avoid personal errors in image interpretation, all procedures were carried out by the same person.

\section{Accuracy assessment}

Two hundred random points were generated within the study area using ArcMapv.10.1 software to consider as reference points for accuracy assessment of the created land use maps under the above three methods. Actual land use type at each point was recorded by using Google Earth and ground verification. An error matrix was prepared for each classified map according to Congalton (2004), with columns and rows representing reference/ ground truth data and classified data, respectively. User's accuracy, which is the probability of a sample point classified on the map actually representing the same class on the ground, is calculated by dividing the total number of correct sample points in a class by the total number of sample points classified in the same class (i.e. row total) on the map. Producer's accuracy, which is the probability of a reference sample point being correctly classified, is calculated by dividing the total number of correctly classified sample points in a class by the total number of sample points of the particular class from reference/ ground truth data (i.e. column total). Finally, the overall accuracy of each method was calculated.

\section{RESULTS AND DISCUSSION}

Land use maps created using the three procedures are shown in Figure 2. Pixel-based classification of Landsat 8 and Google Earth images show a salt-and-pepper effect in final classified images [Figure 2(a) and 2(b)] whereas on-screen digitisation using Google Earth images results in a clean classified image, [Figure 2(c)]. Complexity of the land use architecture in the Hambantota urban area has contributed to the salt-and-pepper effect in the two images of which pixel-based classification technique was applied. This is not uncommon as the class identification operates at each pixel level (Weih \& Riggan, 2010).

Area statistics of each land use class derived from the three methods given in Figure 3 show remarkable differences. Among different land use classes, built-up area has the highest area cover under all three methods as seen in the figure, namely, 3(a) 1225.7 ha, 3(b) 1414.1 ha and 3(c) 1172.6 ha. However, it shows that a difference of 241.5 ha in built-up area between pixel-based classification [03(b)] and on-screen digitisation [03(c)] of the same Google Earth images. It is technically difficult to distinguish settlements and homesteads as separate classes when pixel-based classification is applied, while on-screen polygon drawing facilitates such kind of fine splitting of large classes into several different subclasses. Therefore, all manmade structures (e.g. homesteads, factories, towers) are classified under built-up area in both procedures in order to aid comparisons of areas, and serving as accuracy assessment of the techniques. The lowest land use area has been identified for the class sandy area in all methods and the maximum difference of 112.3 ha can be seen between pixel-based classification of Landsat 8 and on-screen digitisation of Google Earth images. Rest of the classes also show differences in area values derived from the three procedures and in many cases, the maximum difference in area statistics was obtained between pixel-based classification of Landsat 8 and on-screen digitisation of Google Earth images. Differences in area statistics of a particular class under the three methods are mainly due to the difference in spatial resolutions and misinterpretation of spectral data in pixel-based classification.

Among the 200 random points created using ArcMap 10.1 for accuracy estimation of the three methods, two points which were located at polygon boundaries identified during maximum likelihood classification of Landsat approach were excluded from error estimation. Low resolution of Landsat images (i.e. $15 \mathrm{~m}$ after pan sharpening) caused excluding these sample points as the boundary represents $15 \mathrm{~m}$ in this case. However, it was possible to distinguish the land use classes of the two sample points when on-screen digitisation of high resolution Google Earth imagery approach was practiced. This further implies that use of high resolution Google earth imagery could lead to a better performance in identification of polygon boundaries, although the technique is time consuming. Thus, a total of 198 random points were taken into consideration in estimation of errors. A column in each matrix shows the number of sample points of one particular class in actual ground, being classified under different classes in the particular classified map. When pixel-based classification method is compared between Landsat 8 and Google Earth images, out of the 198 random points, only 124 points were accurately classified in Landsat 8 images [sum of diagonal values in Table 1(A)], resulting 


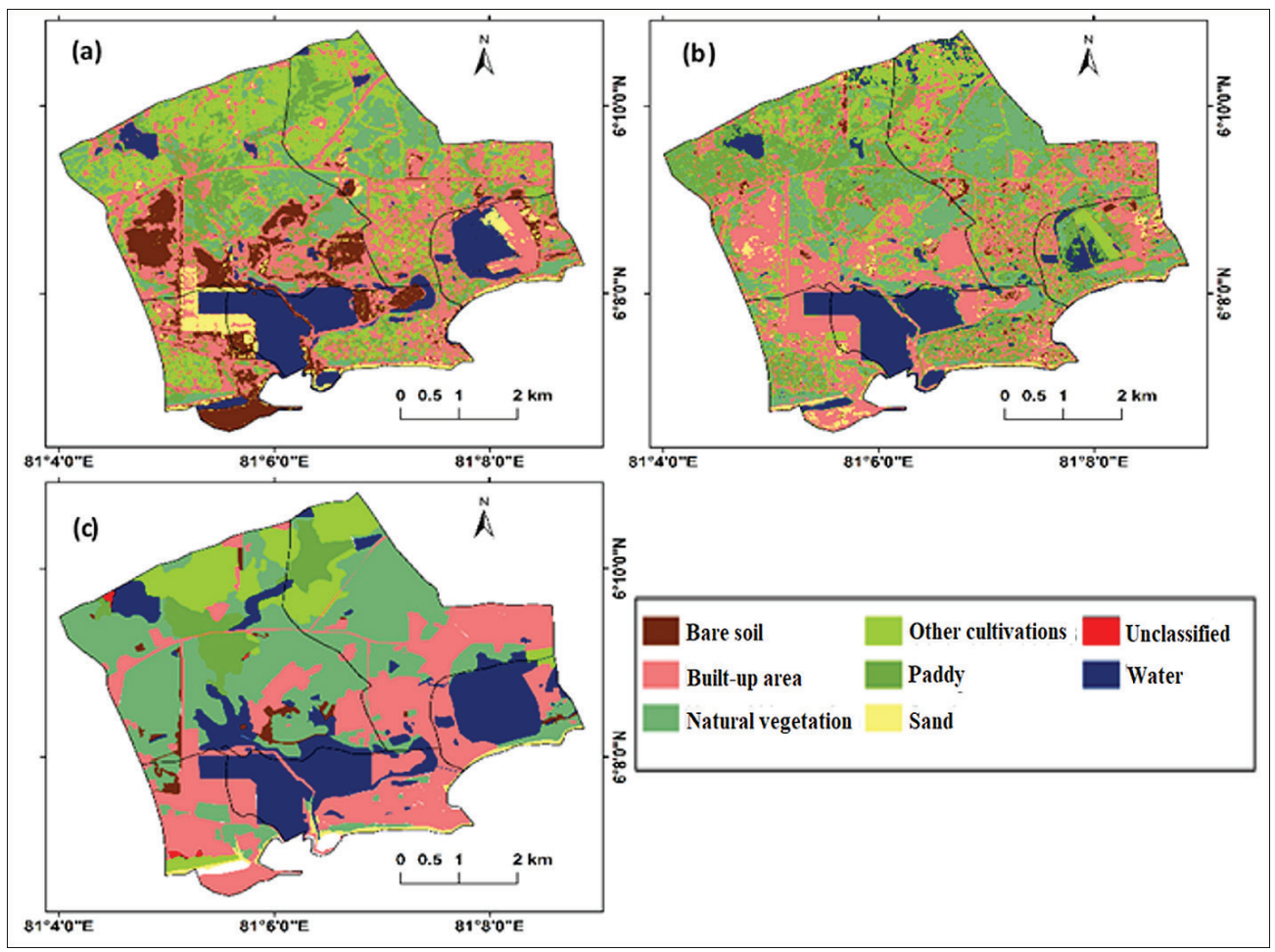

Figure 2: Land use maps of study area: (a) Landsat 8 satellite images using pixel-based classification; (b) Google Earth images using pixel-based classification and (c) Google Earth images using on-screen digitisation.

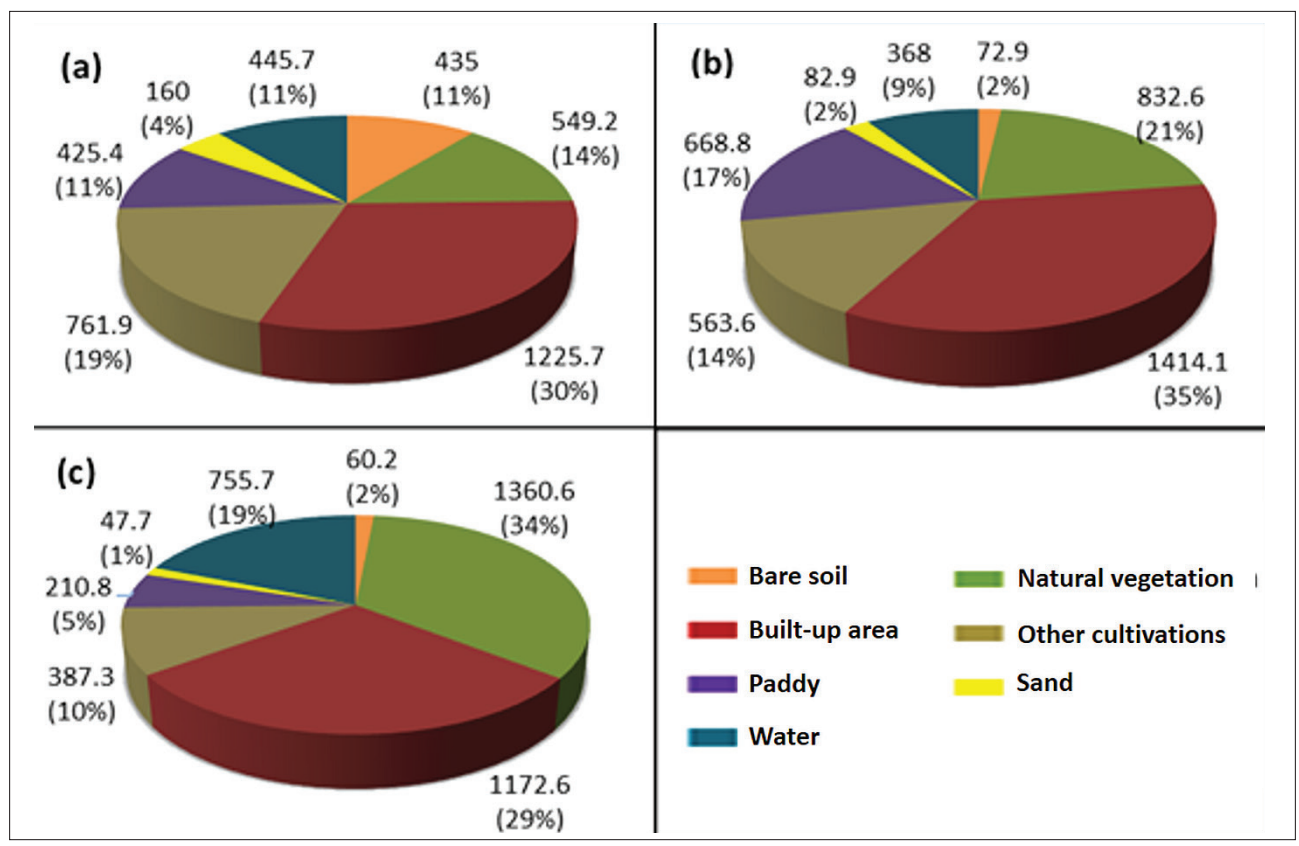

Figure 3: Area (in ha) and percent area of each land use class under three methods: (a) pixel-based classification of Landsat 8 images; (b) pixel-based classification of Google Earth images and (c) on-screen digitisation of Google Earth images. 
in an overall accuracy of $62.6 \%$ whereas only 117 points were accurately classified in Google Earth imagery [sum of diagonal values in Table 1(B)] resulting in a 59.1\% overall accuracy. On-screen digitisation of Google Earth imagery contained 175 accurately classified points [sum of diagonal values in Table $1(\mathrm{C})$ ] resulting in the highest overall accuracy of $88.4 \%$. Therefore, the land use map created by on-screen digitisation method using Google Earth images increased the overall accuracy over the land use maps created by pixel-based classification using Landsat 8 and Google Earth images by $25.8 \%$ and $29.3 \%$, respectively. Table 1 shows that when pixel-based classification technique is used, high spatial resolution Google Earth imagery results in a lower accuracy than the moderate resolution Landsat imagery. Therefore, it proves that using a high spatial resolution image itself is not enough to produce a land use/cover map with a good classification accuracy when pixel-based approach is used. Thus, moderate resolution images are recommended to be used with pixel-based classification technique in urban mapping.

Pixel-based classification method provides lower accuracies (less than $50 \%$ ) for the land use classes paddy, sand and minor crops for both Landsat 8 and Google images (Table 1 and Figure 4) whereas on-screen digitisation of Google Earth images provides an increased user's accuracy for the same land use classes; paddy $92 \%$, sand - $86 \%$ and minor crops- $80 \%$. However, pixel-based classification of Landsat 8 and on-screen digitisation of Google Earth images provide similar user's accuracies as $82 \%$ and $88 \%$, respectively, for the natural vegetation land use class. Thus, it is apparent that classification accuracies of certain classes are reduced when the pixel-based classification is used with high resolution Google images in place of moderate resolution Landsat 8 images. Pixel-based classification considers only the spectral information in its technique and the user has limited control over classification, whereas onscreen digitisation takes several image attributes, size, shape, texture, shadows, associated land uses etc., into consideration when allocating a polygon into a certain land use class (Campbell \& Wynne, 2011). This leads to increased classification accuracy for all land use classes when on-screen digitisation is used.

Scientists use high-resolution multi-temporal global urban land maps to provide reliable information for global urban research and other associated activities (Zhang \& Weng, 2016; Liu et al., 2018). Most of these are not affordable to scientists in developing countries due to their high cost. In addition, many researchers have reported several challenges like image selection scheme, establishment of an efficient platform for image data processing, and more importantly, development of adequate image classification methods, which are commonly accessible when using Landsat images (Bagan \& Yamagata, 2012; Li et al., 2015). Under such condition, Liu et al. (2018) has recommended to use Google Earth to confront the aforementioned challenges. When considering all these facts, it is worthwhile to develop a robust methodology, which includes freely accessible image sources with compatible image classification systems for users. Since the user manually identifies and digitises land use polygons in on-screen digitisation method, images having high level of details is an advantage to correctly identify the polygons. This is the reason for higher classification accuracy, particularly producer's accuracy, when on-screen digitisation is applied for Google Earth images. Although on-screen digitisation results in higher classification accuracy, the time consuming nature restricts its application on very large areas (Ye et al., 2006). When the classification accuracy of each land use class in the three methods is considered, the class water has been classified with a high accuracy range of $81-100 \%$. Although water bodies and saltpans are distinguishable in Google Earth images, they lead to misinterpretation in moderate resolution Landsat 8 images. Hence, all water surfaces (i.e. canals, waterholes, streams, saltpans) are classified under water in both pixel-based and on-screen digitisation procedures. Large cemented land areas, such as construction sites where the Hambantota port and the other developmental projects take place, are categorised in pixel-based classification under land use class sand due to high reflectance of cemented surfaces, which results in low producer's $(25-44 \%)$ and user's accuracy $(25-47 \%)$. Nevertheless, in on-screen digitisation, these areas are distinguishable by their grey colour and coarse texture, thus omitting the misclassification and resulting in high accuracies ( $75 \%$ producer's and $86 \%$ user's) in that particular land use class. Thus, pixel-based classification shows a higher area for the class 'sand' of about 160 ha, compared to a lower area resulting from on-screen digitation of about 47 ha. Misidentification of pixels belong to paddy lands and minor crops due to similarities in attributes (e.g. colour and size) has caused an increase of mapping error in both these classes in pixel-based classification of Landsat 8 and Google Earth images. Ground observations revealed the presence of Casuarina plantations near Hambantota port area, which could have appeared similar to natural vegetation when classifying both Landsat 8 and Google Earth images leading to misclassification. Correct identification of such 
Table 1: Error matrices for the land use map prepared with (A) pixel-based classification of Landsat 8 images; (B) pixel-based classification of Google Earth images and (C) on-screen digitisation of Google Earth images.

\begin{tabular}{|c|c|c|c|c|c|c|c|c|c|c|}
\hline \multirow[b]{2}{*}{ (A) } & \multirow[b]{2}{*}{ Classes } & \multirow[b]{2}{*}{$\begin{array}{c}\text { Bare } \\
\text { soil }\end{array}$} & \multirow[b]{2}{*}{$\begin{array}{l}\text { Built-up } \\
\text { area }\end{array}$} & \multicolumn{3}{|c|}{ Reference/ ground truth data } & \multirow[b]{2}{*}{ Sand } & \multirow[b]{2}{*}{ Water } & \multirow[b]{2}{*}{$\begin{array}{l}\text { Raw } \\
\text { total }\end{array}$} & \multirow[b]{2}{*}{$\begin{array}{c}\text { User's } \\
\text { accuracy } \\
\%\end{array}$} \\
\hline & & & & $\begin{array}{c}\text { Natural } \\
\text { vegetation }\end{array}$ & $\begin{array}{l}\text { Minor } \\
\text { crops }\end{array}$ & Paddy & & & & \\
\hline \multirow{9}{*}{$\begin{array}{l}\text { Classified } \\
\text { data }\end{array}$} & Bare soil & 14 & 2 & 0 & 1 & 1 & 2 & 0 & 20 & 70 \\
\hline & Built-up area & 3 & 35 & 2 & 3 & 2 & 9 & 1 & 55 & 64 \\
\hline & $\begin{array}{l}\text { Natural } \\
\text { vegetation }\end{array}$ & 0 & 1 & 27 & 2 & 3 & 0 & 0 & 33 & 82 \\
\hline & Minor crops & 1 & 0 & 5 & 12 & 6 & 0 & 1 & 25 & 48 \\
\hline & Paddy & 0 & 1 & 8 & 5 & 3 & 0 & 0 & 17 & 18 \\
\hline & Sand & 3 & 7 & 0 & 1 & 0 & 4 & 1 & 16 & 25 \\
\hline & Water & 0 & 0 & 0 & 0 & 2 & 1 & 29 & 32 & 91 \\
\hline & Column total & 21 & 46 & 42 & 24 & 17 & 16 & 32 & 198 & \\
\hline & $\begin{array}{l}\text { Producer's } \\
\text { accuracy } \%\end{array}$ & 67 & 76 & 64 & 50 & 18 & 25 & 91 & & \\
\hline & \multicolumn{10}{|c|}{ Reference/ ground truth data } \\
\hline (B) & Classes & $\begin{array}{c}\text { Bare } \\
\text { soil }\end{array}$ & $\begin{array}{c}\text { Built-up } \\
\text { area }\end{array}$ & $\begin{array}{c}\text { Natural } \\
\text { vegetation }\end{array}$ & $\begin{array}{l}\text { Minor } \\
\text { crops }\end{array}$ & Paddy & Sand & Water & $\begin{array}{l}\text { Raw } \\
\text { total }\end{array}$ & $\begin{array}{c}\text { User's } \\
\text { accuracy } \\
\%\end{array}$ \\
\hline \multirow{9}{*}{$\begin{array}{l}\text { Classified } \\
\text { data }\end{array}$} & Bare soil & 12 & 1 & 0 & 0 & 1 & 2 & 0 & 16 & 75 \\
\hline & Built-up area & 3 & 35 & 7 & 2 & 1 & 7 & 1 & 56 & 63 \\
\hline & $\begin{array}{l}\text { Natural } \\
\text { vegetation }\end{array}$ & 2 & 3 & 25 & 5 & 6 & 0 & 3 & 44 & 57 \\
\hline & Minor crops & 1 & 1 & 5 & 9 & 5 & 0 & 0 & 21 & 43 \\
\hline & Paddy & 0 & 1 & 5 & 8 & 3 & 0 & 2 & 19 & 16 \\
\hline & Sand & 3 & 5 & 0 & 0 & 0 & 7 & 0 & 15 & 47 \\
\hline & Water & 0 & 0 & 0 & 0 & 1 & 0 & 26 & 27 & 96 \\
\hline & Column total & 21 & 46 & 42 & 24 & 17 & 16 & 32 & 198 & \\
\hline & $\begin{array}{l}\text { Producer's } \\
\text { accuracy } \%\end{array}$ & 57 & 76 & 60 & 38 & 18 & 44 & 81 & & \\
\hline & \multicolumn{10}{|c|}{ Reference/ ground truth data } \\
\hline (C) & Classes & $\begin{array}{c}\text { Bare } \\
\text { soil }\end{array}$ & $\begin{array}{c}\text { Built-up } \\
\text { area }\end{array}$ & $\begin{array}{c}\text { Natural } \\
\text { vegetation }\end{array}$ & $\begin{array}{l}\text { Minor } \\
\text { crops }\end{array}$ & Paddy & Sand & Water & $\begin{array}{l}\text { Raw } \\
\text { total }\end{array}$ & $\begin{array}{c}\text { User's } \\
\text { accuracy } \\
\%\end{array}$ \\
\hline \multirow{9}{*}{$\begin{array}{l}\text { Classified } \\
\text { data }\end{array}$} & Bare soil & 17 & 1 & 0 & 0 & 0 & 1 & 0 & 19 & 89 \\
\hline & Built-up area & 1 & 45 & 2 & 1 & 1 & 3 & 0 & 53 & 85 \\
\hline & $\begin{array}{l}\text { Natural } \\
\text { vegetation }\end{array}$ & 1 & 0 & 38 & 2 & 2 & 0 & 0 & 43 & 88 \\
\hline & Minor crops & 0 & 0 & 2 & 20 & 3 & 0 & 0 & 25 & 80 \\
\hline & Paddy & 0 & 0 & 0 & 1 & 11 & 0 & 0 & 12 & 92 \\
\hline & Sand & 2 & 0 & 0 & 0 & 0 & 12 & 0 & 14 & 86 \\
\hline & Water & 0 & 0 & 0 & 0 & 0 & 0 & 32 & 32 & 100 \\
\hline & Column total & 21 & 46 & 42 & 24 & 17 & 16 & 32 & 198 & \\
\hline & $\begin{array}{l}\text { Producer's } \\
\text { accuracy } \%\end{array}$ & 81 & 98 & 90 & 83 & 65 & 75 & 100 & & \\
\hline
\end{tabular}




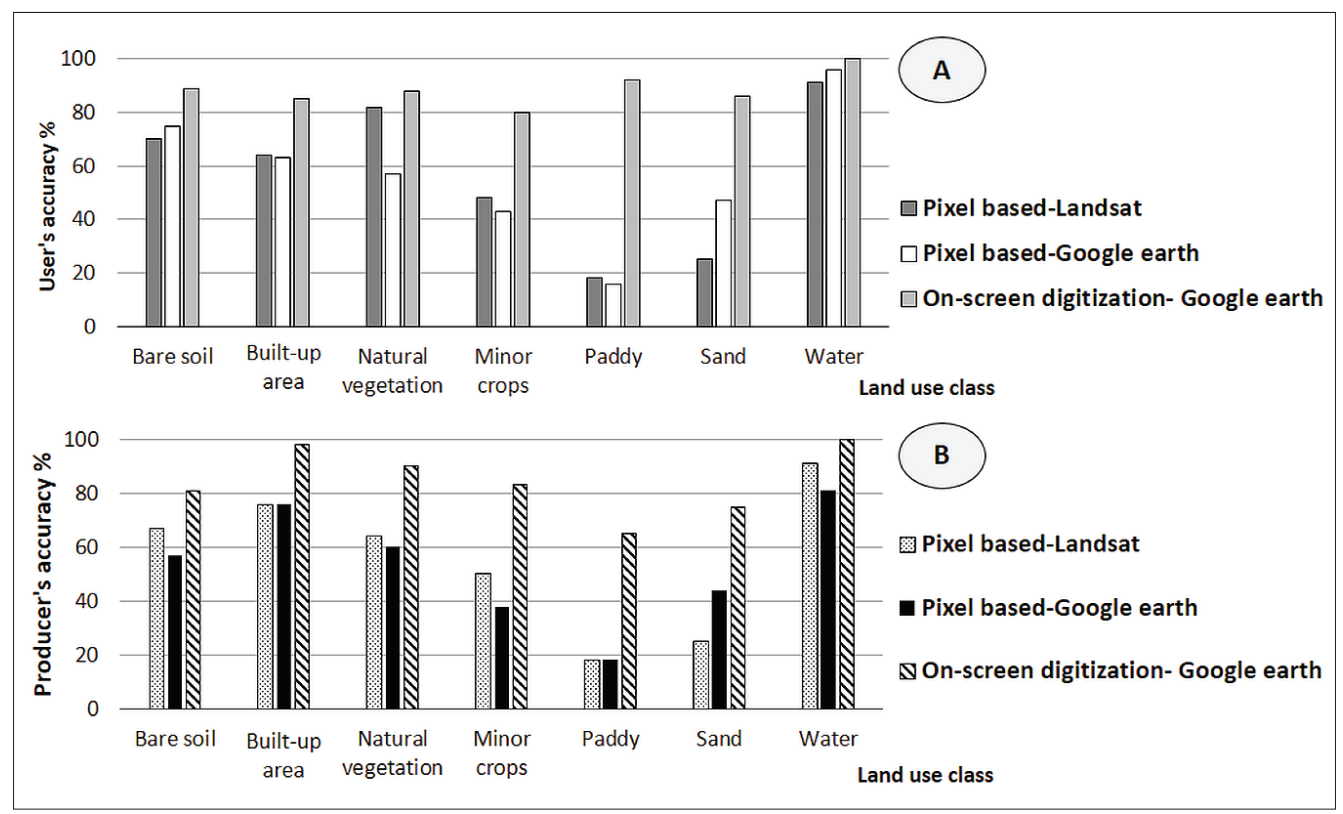

Figure 4: Comparison of percentage accuracies; (A) user's accuracy and (B) producer's accuracy of each land use class under three procedures followed in the study.

dense vegetation cover is difficult at this level of spatial resolution. A higher accuracy of natural vegetation in pixel-based classification of Landsat 8 over Google Earth images could be due to the broad spectral information that exists for natural vegetation in Landsat 8 images. Similarly, water areas/bodies were also identified with a high accuracy in all combinations due to the fact that spectral information and other image specific attributes (e.g. tonality, texture) are much explicit to water land use class. Although the classification accuracies are relatively high in water land use class, the area statistics showed a much higher difference (368 ha-755.7 ha) under three methods (Figure 3). This is because the classification values depend on the positioning of sample points.

Google Earth allows the user to download images at any preferred eye altitude. The user can decide the relevant eye altitude to take the total area to be covered and also the required resolution for image processing. Lower eye altitudes may cover a small area but resulting in high image resolution when the obtained images are geo-referenced and vice versa. In this study, the images were downloaded at $4 \mathrm{~km}$ eye altitude, which gave the best resolution for identifying different land uses. All images were downloaded at the same eye altitude to avoid geometric error. The images downloaded from both sources were in the same weather season of Sri Lanka (rainy season) thereby eliminating the chances of error that can occur due to seasonal variations in land uses.

\section{CONCLUSION}

According to the results obtained for Hambantota urban area, the pixel-based classification method shows lower accuracy when applied to both Landsat 8 and Google Earth images and it worsens with high resolution Google Earth images. In contrast, on-screen digitisation of Google Earth images increases map classification accuracy for all types of land use classes in the study area. However, this application is recommended for smaller urban areas due to high time consumption involved in user's end. Therefore, use of Google Earth imagery coupled with on-screen digitisation method can be recommended as a cost-effective source and high accuracy method for mapping smaller urban areas using remotely sensed images, particularly for developing countries.

\section{Acknowledgement}

This research was funded by the Faculty of Science, University of Ruhuna. 


\section{REFERENCES}

Bagan H. \& Yamagata Y. (2012). Landsat analysis of urban growth: how Tokyo became the world's largest megacity during the last 40 years. Remote Sensing of Environment 127: $210-222$.

DOI: https://doi.org/10.1016/j.rse.2012.09.011

Campbell J.B. \& Wynne R.H. (2011). Introduction to Remote Sensing, $5^{\text {th }}$ edition, pp. 667. Guilford Press, New York, USA.

Congalton R.G. (2004). Putting the map back in map accuracy assessment. In: Remote Sensing and GIS Accuracy Assessment (eds. R.S. Lunetta \& J.G. Lyon), pp. 1-13. CRC press, USA.

DOI: https://doi.org/10.1201/9780203497586.ch1

Eastman J.R. (1999). Guide to GIS and Image Processing. IDRISI 32 User Guide 2, Clark Labs, Clark University, Worcester.

Gong P., Wang J., Yu L., Zhao Y., Zhao Y., Liang L., Niu Z., Huang X., Fu H. \& Liu S. (2013). Finer resolution observation and monitoring of global land cover: first mapping results with Landsat TM and ETM+ data. International Journal of Remote Sensing 34: 2607-2654. DOI: https://doi.org/10.1080/01431161.2012.748992

López-Moreno J.I. et al. (15 authors) (2019). Ground-based remote-sensing techniques for diagnosis of the current state and recent evolution of the Monte Perdido Glacier, Spanish Pyrenees. Journal of Glaciology 65(249): 85-100. DOI: https://doi.org/10.1017/jog.2018.96

Herold M., Clarke K.C. \& Scepan J. (2002). Remote sensing and landscape metrics to describe structures and changes in urban land use. Environment and Planning 34: 1443-1458. DOI: https://doi.org/10.1068\%2Fa3496

Hu Q., Wu W., Xia T., Yu Q., Yang P., Li Z. \& Song Q. (2013). Exploring the use of Google Earth imagery and objectbased methods in land use/cover mapping. Remote Sensing 5: 6026-6042. DOI: https://doi.org/10.3390/rs5116026

Huang C., Goward S.N., Schleeweis K., Thomas N., Masek J.G.\& Zhu Z. (2009). Dynamics of national forests assessed using the Landsat record: case studies in eastern United States. Remote Sensing of Environment 113: 1430-1442. DOI: https://doi.org/10.1016/j.rse.2008.06.016

Jensen J.R. \& Cowen D.C. (1999). Remote sensing of urban/ suburban infrastructure and socioeconomic attributes. Photogrammetric Engineering and Remote Sensing 65: 611-622.

Li X., Gong P. \& Liang L. (2015). A 30-year (1984-2013) record of annual urban dynamics of Beijing City derived from Landsat data. Remote Sensing of Environment 166: 78-90.

DOI: https://doi.org/10.1016/j.rse.2015.06.007

Liu X., Hu G., Chen Y., Li X., Xu X., Li S., Pei F. \& Wang S. (2018). High-resolution multi-temporal mapping of global urban land using Landsat images based on the Google Earth Engine Platform. Remote Sensing of Environment 209: $227-239$.

DOI: https://doi.org/10.1016/j.rse.2018.02.055
Lu D. \& Weng Q. (2007). A survey of image classification methods and techniques for improving classification performance. International Journal of Remote Sensing 28(5): 823-870.

DOI: https://doi.org/10.1080/01431160600746456

Mering C., Baro J .\& Upegui E. (2010). Retrieving urban areas on Google Earth images: application to towns of West Africa. International Journal of Remote Sensing 31: 5867-5877.

DOI: https://doi.org/10.1080/01431161.2010.512311

Myint S.W., Gober P., Brazel A., Grossman-Clarke S. \& Weng Q. (2011). Per-pixel vs. object-based classification of urban land cover extraction using highspatial resolution imagery. Remote Sensing of Environment 115(5): 1145-1161. DOI: https://doi.org/10.1016/j.rse.2010.12.017

Otukei J.R. \& Blaschke T. (2010). Land cover change assessment using decision trees, support vector machines and maximum likelihood classification algorithms. International Journal of Applied Earth Observation and Geoinformation 12(1): S27-S31.

DOI: https://doi.org/10.1016/j.jag.2009.11.002

Pahlevan N., Schott J.R., Franz B.A., Zibordi G., Markham B., Bailey S., Schaaf C.B., Ondrusek M., Greb S. \& Strait C.M. (2017). Landsat 8 remote sensing reflectance (Rrs) products: evaluations, intercomparisons, and enhancements. Remote Sensing of Environment 190: 289-301.

DOI: http://dx.doi.org/10.1016/j.rse.2016.12.030

Phinn S.R., Menges C., Hill G.J.E. \& Stanford, M. (2000). Optimizing remotely sensed solutions for monitoring, modeling, and managing coastal environments. Remote Sensing of Environment 73: 117-132.

DOI: https://doi.org/10.1016/S0034-4257(00)00087-0

Phua M., Tsuyuki S., Furuy N. \& Lee J.S. (2008). Detecting deforestation with a spectral change detection approach using multitemporal Landsat data: a case study of Kinabalu Park, Sabah, Malaysia. Journal of Environmental Management 88: 784-795.

DOI: https://doi.org/10.1016/j.jenvman.2007.04.011

Potere D., Schneider A., Angel S. \& Civco D.L. (2009). Mapping urban areas on a global scale: which of the eight maps now available is more accurate? International Journal of Remote Sensing 30: 6531-6558. DOI: https://doi.org/10.1080/01431160903121134

Reddy M.A. (2008). Remote Sensing and Geographical Information Systems, $2^{\text {nd }}$ edition, pp. 440. BS publications, Hyderabad, India.

Remus P., Igor S. \& Daniel P. (2014). Detecting climate change effects on forest ecosystems in Southwestern Romania using Landsat TM NDVI data. Journal of Geographical Sciences 24(5): 815-832. DOI: https://doi.org/10.1007/s11442-014-1122-2

Schneider A., Friedl M.A. \& Potere D. (2010). Mapping global urban areas using MODIS 500-m data: new methods and datasets based on 'urban ecoregions'. Remote Sensing of Environment 114: 1733-1746.

DOI: https://doi.org/10.1016/j.rse.2010.03.003

Sexton J.O., Song X.-P., Huang C., Channan S., Baker M.E. \& Townshend J.R. (2013). Urban growth of the Washington, 
DC-Baltimore, MD metropolitan region from 1984 to 2010 by annual, Landsat-based estimates of impervious cover. Remote Sensing of Environment 129: 42-53. DOI: https://doi.org/10.1016/j.rse.2012.10.025

Shalaby A. (2012). Assessment of urban sprawl impact on the agricultural land in the Nile Delta of Egypt using remote sensing and digital soil map. International Journal of Environment and Sciences 1(4): 253-62.

Shivakumar B.R. \& Rajashekararadhya S.V. (2018). Investigation on land cover mapping capability of maximum likelihood classifier: a case study on North Canara, India. Procedia Computer Science 143: 579-586. DOI: https://doi.org/10.1016/j.procs.2018.10.434

Sivanpillai R. \& Miller S.N. (2008). Benefits of pan-sharpened Landsat imagery for mapping small waterbodies in the Powder River Basin, Wyoming, USA. Lakes and Reservoirs 13(1): 69-76.

DOI: https://doi.org/10.1111/j.1440-1770.2007.00356.x

Song X.P., Sexton J.O., Huang C., Channan S. \& Townshend J.R. (2016). Characterizing the magnitude, timing and duration of urban growth from time series of Landsat based estimates of impervious cover. Remote Sensing of Environment 175: 1-13. DOI: https://doi.org/10.1016/j.rse.2015.12.027

Sun Z., Wang C., Guo H. \& Shang R. (2017). A modified normalized difference impervious surface index (MNDISI) for automatic urban mapping from Landsat imagery. Remote Sensing 9(942): 1-18.

DOI:https://doi.org/10.3390/rs9090942

Thapa R.B. \& Murayama Y. (2009). Urban mapping, accuracy, and image classification: a comparison of multiple approaches in Tsukuba City, Japan. Applied Geography 29(1): 135-144.

DOI: https://doi.org/10.1016/j.apgeog.2008.08.001

Warnasuriya T.W.S., Gunaalan K., Gunasekara S.S. (2018). Google Earth: a new resource for shoreline change estimation-case study from Jaffna Peninsula, Sri Lanka. Marine Geodesy 41(6): 546-580.

DOI: https://doi.org/10.1080/01490419.2018.1509160

Weih R.C. Jr. \& Riggan N.D. Jr. (2010). Object-based classification vs. pixel-based classification: comparitive importance of multi-resolution imagery. The International Archives of the Photogrammetry, Remote Sensing and Spatial Information Sciences 38(4): C7.

Ye Q.H., Kang S.C., Chen F. \& Wang J.H. (2006). Monitoring glacier variations on Geladandong mountain, central Tibetan Plateau, from 1969 to 2002 using remote sensing and GIS technologies. Journal of Glaciology 52(179): 537-545.

DOI: https://doi.org/10.3189/172756506781828359

Yu L. \& Gong P. (2011). Google Earth as a virtual globe tool for Earth science applications at the global scale: progress and perspectives. International Journal of Remote Sensing 33: 3966-3986.

DOI: https://doi.org/10.1080/01431161.2011.636081

Zhang L. \& Weng Q. (2016). Annual dynamics of impervious surface in the Pearl River Delta, China, from 1988 to 2013, using time series Landsat imagery. ISPRS Journal of Photogrammetry and Remote Sensing 113: 86-96.

DOI: https://doi.org/10.1016/j.isprsjprs.2016.01.003 